\title{
Selective removal of sodium from alkali-metal solutions with tetraoctylammonium monensin
}

Citation for published version (APA):

Parmentier, D., Lavenas, M., Güler, E., Metz, S. J., \& Kroon, M. C. (2016). Selective removal of sodium from alkali-metal solutions with tetraoctylammonium monensin. Desalination, 399, 124-127.

https://doi.org/10.1016/j.desal.2016.08.018

DOI:

10.1016/j.desal.2016.08.018

Document status and date:

Published: 01/12/2016

Document Version:

Accepted manuscript including changes made at the peer-review stage

Please check the document version of this publication:

- A submitted manuscript is the version of the article upon submission and before peer-review. There can be important differences between the submitted version and the official published version of record. People interested in the research are advised to contact the author for the final version of the publication, or visit the $\mathrm{DOI}$ to the publisher's website.

- The final author version and the galley proof are versions of the publication after peer review.

- The final published version features the final layout of the paper including the volume, issue and page numbers.

Link to publication

\section{General rights}

Copyright and moral rights for the publications made accessible in the public portal are retained by the authors and/or other copyright owners and it is a condition of accessing publications that users recognise and abide by the legal requirements associated with these rights.

- Users may download and print one copy of any publication from the public portal for the purpose of private study or research.

- You may not further distribute the material or use it for any profit-making activity or commercial gain

- You may freely distribute the URL identifying the publication in the public portal.

If the publication is distributed under the terms of Article 25fa of the Dutch Copyright Act, indicated by the "Taverne" license above, please follow below link for the End User Agreement:

www.tue.nl/taverne

Take down policy

If you believe that this document breaches copyright please contact us at:

openaccess@tue.nl

providing details and we will investigate your claim. 


\title{
Selective removal of sodium from alkali-metal solutions with tetraoctylammonium monensin
}

\author{
Dries Parmentier, ${ }^{a, b}$ Magali Lavenas, ${ }^{b}$ Enver Güler, ${ }^{b, c}$ Sybrand J. Metz ${ }^{b}$ and Maaike C. \\ Kroon $^{a, d, *}$
}

10 a Separation Technology Group
Department of Chemical Engineering and Chemistry

Eindhoven University of Technology

5612 AZ Eindhoven, The Netherlands

${ }^{\mathrm{b}}$ Wetsus

European Centre of Excellence for Sustainable Water Technology

8911 MA Leeuwarden, The Netherlands

${ }^{\mathrm{c}}$ Nanotechnology Research and Application Center

Sabanc1 University

34956 Istanbul, Turkey

${ }^{\mathrm{d}}$ Petroleum Institute University \& Research Center

Bu Hasa Building, Room 2-203

P.O. Box 2533, Abu Dhabi, UAE 


\begin{abstract}
Accumulation of sodium ions in fresh water limits its use for drinking water. In the greenhouse industry reuse of irrigation water, which still contains valuable nutrients is limited due to an increasing sodium concentration, and next to this high concentrations of sodium also result in corrosion problems. Existing technologies are not yet able to selectively remove sodium to solve above mentioned problems. Therefore, it was tried to develop a novel sodium selective ionic liquid based on the monensin anion combined with the tetraoctylammonium cation. Ionic crystals were obtained instead of an ionic liquid. Nevertheless, it was proven that these crystals could selectively remove sodium. Metal extraction experiments of an aqueous solution containing $\mathrm{Li}$, $\mathrm{Na}, \mathrm{K}, \mathrm{Mg}$ and Ca with the monensin ionic crystals dissolved in toluene showed a selective single stage extraction efficiency of $41 \mathrm{wt} \%$ for sodium, while the extraction of the other salts was negligible. Regeneration is possible by applying an acidic solution, however this also prevents its reuse.
\end{abstract}

${ }_{15} \quad$ Keywords: ionic liquids, tetraoctylammonium monensin, selective sodium extraction, sodium monensin, ionic crystals 


\section{Introduction}

High concentrations of sodium in water (>20 mg/L) limit its use for drinking water [1-3]. The reuse of the irrigation water in greenhouses is limited by the accumulation of sodium ions. This irrigation water, still containing valuable plant nutrients, is often discharged to the environment as a brine stream [4,5]. Industrial water containing too much sodium on the other hand leads to corrosion problems [6]. However, up to now there is still no cost-effective industrial technology that can selectively remove sodium.

Ionic liquids (ILs) are organic solvents consisting entirely of ions. The strong electrostatic forces in these solvents result in a low volatility and low flammability. Due to these properties, ILs were selected as ideal replacements for volatile organic solvents, which are common in industry [7-13]. Furthermore, by selecting the right organic ions to synthesize the IL, one can obtain an IL that is ideal for metal extraction. It has already been proven that some ILs show excellent efficiencies for the extraction of transition and rare earth metals from aqueous phases, but less attention has been given to the extraction of alkali metals [14-20]. Attempts to facilitate alkali metal extraction have been made by adding crown ethers, aza-crown ethers and calixarenes to hydrophobic ionic liquids [21-27]. Unfortunately, analysis of the extraction mechanism showed that in these cases alkali metal extraction was based on ion-exchange, resulting in the loss of the cation of the IL into the aqueous phase, which is not sustainable [28].

Task-specific ionic liquids (TSILs) for metal extraction were developed to avoid ionexchange processes, and the leakage of the cation of the ILs into the aqueous phases during metal extraction [29-33]. In these TSILs a metal binding functionality was incorporated into the cation or anion. In case of alkali metal extraction mostly ether functionalities were incorporated [34,35].

Monensin is an alternative organic extractant, which has specific affinity towards sodium [36,37]. Its structure is related to crown-ethers in which a sodium ion can be encircled. Monensin 
and its derivatives have already been tested to make sodium selective membranes, but an IL with monensin as anion has not been reported before [38].

In this research, an ionic crystal was developed using monesin as an anion. The synthesized crystal was then tested for selective sodium removal from a mixed salt solution containing the most common metal cations in drinking and irrigation water, i.e. lithium, sodium, potassium, magnesium and calcium. Performance was compared with sodium monensin and 2hydroxymethyl-15-crown-5, see figure 1 . Additional tests were performed to characterize the regeneration and reuse of the monensin based ionic crystal.

\section{Experimental}

\section{Materials}

The extractant tetraoctylammonium monensin ([N $\left.\mathrm{N}_{8888}\right][$ monensin]) used in this research was synthesized with reagents purchased from Sigma-Aldrich: sodium monensin (90-95\%) and tetraoctylammonium chloride $(\geq 97 \%)$. All inorganic salts used had a purity above $>98 \%$. Magnesium chloride hexahydrate $\left(\mathrm{MgCl}_{2} \cdot 6 \mathrm{H}_{2} \mathrm{O}\right)$ and 2-hydroxymethyl-15-crown-5 (95\%) were also delivered by Sigma-Aldrich. Toluene, sodium chloride ( $\mathrm{NaCl})$, calcium(II) chloride dihydrate $\left(\mathrm{CaCl}_{2} \cdot 2 \mathrm{H}_{2} \mathrm{O}\right)$ and potassium chloride $(\mathrm{KCl})$ were obtained from VWR-ProLabo. Lithium chloride (LiCl) was purchased from Merck. MilliQ water ( $\geq 18.2 \mathrm{M} \Omega . \mathrm{cm})$ used throughout the synthesis was obtained by a Millipore MilliQ ${ }^{\circledR}$ biocel, which used a Q-grade ${ }^{\circledR}$ column.

\section{Synthesis of the extractant}

[ $\left.\mathrm{N}_{8888}\right][$ monensin] was obtained by adding tetraoctylammonium chloride $(1.17 \mathrm{~g}, 2.33$ mmol) diluted in $50 \mathrm{~mL}$ toluene to an aqueous solution of an equimolar amount of monensin salt (1.61 g, $2.33 \mathrm{mmol}, 50 \mathrm{~mL}$ ). The solution was then stirred for $3 \mathrm{~h}$ at room temperature. The 
organic phase was washed with water in order to remove the remaining sodium and chloride (6 times with $50 \mathrm{~mL}$ MilliQ water). The residual chloride content was confirmed to be negligibly low by adding $\mathrm{AgNO}_{3}$ to the last water phase and observing that no $\mathrm{AgCl}$ precipitated. Toluene was removed under reduced pressure using a rotary evaporator (BUNCHI Rotavapor ${ }^{\circledR} \mathrm{R}-3$ ) at $50{ }^{\circ} \mathrm{C}$. The product was obtained in the form of a white powder (2.936 g). Yield: 92\% MS (ESI): Calculated for $\left[\mathrm{N}_{8888}\left(\mathrm{C}_{32} \mathrm{H}_{68} \mathrm{~N}\right)\right]^{+} \mathrm{m} / \mathrm{z}$ : 467.0; found m/z: 466.7 and calculated for [Monensin $\left.\left(\mathrm{C}_{36} \mathrm{H}_{61} \mathrm{O}_{11}\right)\right]^{-} \mathrm{m} / \mathrm{z}$ : 669.9; found m/z: 669.4. Elemental analysis found (\%): C, 73.0; $\mathrm{H}$, 11.6; N, 1.41; calc. for $\mathrm{C}_{68} \mathrm{H}_{129} \mathrm{O}_{11} \mathrm{~N}$ : C, 71.85; H, 11.44; N, 1.23; O, 15.48. $T_{\mathrm{m}}>378 \mathrm{~K}$, two degradation points were observed $T_{\mathrm{d}}=463 \mathrm{~K}$ and $552 \mathrm{~K}$.
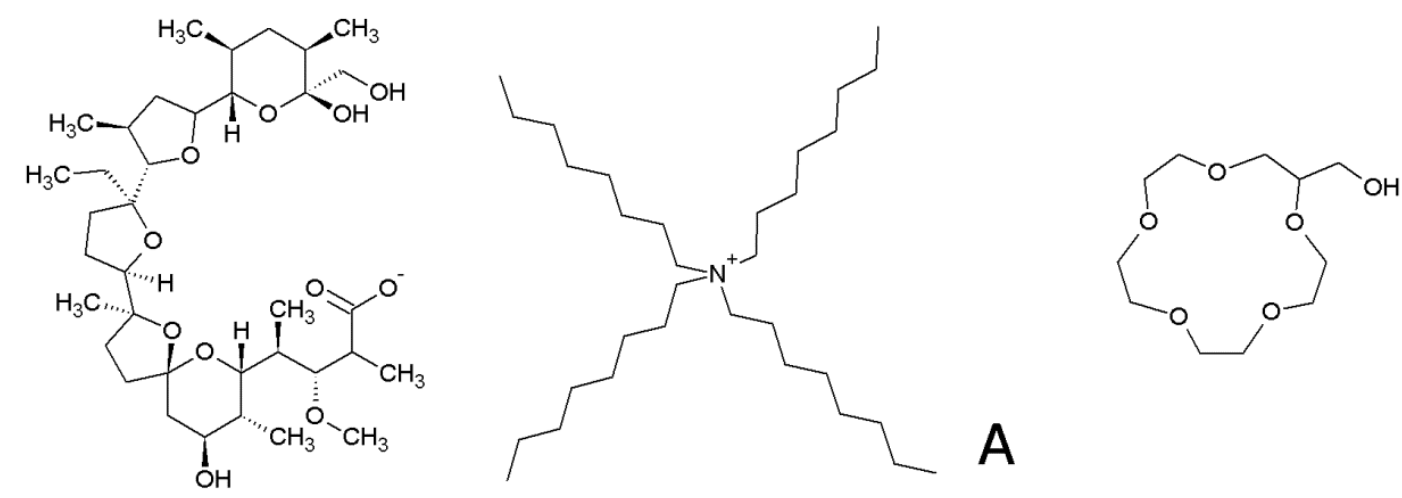

Figure 1. A) the extractant tetraoctylammonium monensin, $\left[\mathrm{N}_{8888}\right][$ monensin] first reported here B) the structure of 2-hydroxymethyl-15-crown-5.

\section{Characterization of the ionic crystal $\left[\mathbf{N}_{\mathbf{8 8 8 8}}\right][$ monensin]}

The purity of the ionic crystal was determined using ${ }^{1} \mathrm{H}$ NMR on a $400 \mathrm{MHz}$ Bruker nuclear magnetic resonance (NMR) spectrometer. The decomposition temperature was determined with a thermogravimetric analysis (TGA) Q 500 apparatus (TA instruments, USA) at a scan rate of 10 $\mathrm{K} \cdot \mathrm{min}^{-1}$ under a nitrogen flow. The thermograms were analyzed with TG instruments software. Differential scanning calorimetry (DSC) Q 1000, and Perkin Elmer Pyris 1 were used to obtain the melting temperature with a scan rate of $10{ }^{\circ} \mathrm{C} \mathrm{min}^{-1}$. Electrospray-ionisation combined with mass 
spectrometry (ESI-MS) was used to analyze the ionic crystal after synthesis with acetonitrile as eluent. An Agilent Technologies 1200 series ESI-MS was used with acetonitrile:water 90:10 as eluent working with an Agilent mass hunter workstation data acquisition.

\section{Salt extraction and regeneration tests}

Three different metal salt solutions were used to test the extraction efficiency of [N $\left.\mathrm{N}_{8888}\right][$ monensin]. (I) An aqueous sodium chloride solution containing $1 \mathrm{~g} / \mathrm{L} \mathrm{Na}$, (II) an alkali solution containing $1 \mathrm{~g} / \mathrm{L}$ of $\mathrm{KCl}, \mathrm{NaCl}$ and $\mathrm{LiCl}$ and, (III) a mixed alkali and earth alkali solution containing $1 \mathrm{~g} / \mathrm{L}$ of $\mathrm{Li}$ and $2 \mathrm{~g} / \mathrm{L}$ of $\mathrm{Na}, \mathrm{K}, \mathrm{Mg}$ and Ca from their chloride salts. $0.5 \mathrm{~g}$ of [ $\left.\mathrm{N}_{8888}\right][$ monensin] was dissolved in $10 \mathrm{~mL}$ of toluene. For solutions (I) and (III) $1 \mathrm{~mL}$ of the toluene solution and $1 \mathrm{~mL}$ of the salt solution was used. For solution (II) $5 \mathrm{~mL}$ of the toluene solution was mixed with $5 \mathrm{~mL}$ salt solution. Extraction of the first salt solution was also repeated for an equimolar amount of sodium monensin or 2-hydroxymethyl-15-crown-5 dissolved in toluene. To quantify regeneration, $1 \mathrm{~mL}$ aliquots were taken from used extractant $(5 \mathrm{~mL}$ toluene exposed to salt (II)) and subsequently mixed with either: $1 \mathrm{~mL}$ of a $0.1 \mathrm{M} \mathrm{HCl}$ solution, a $0.1 \mathrm{M}$ acetic acid solution or, MilliQ water. These samples were stirred for $2 \mathrm{~h}$ on a vortex mixer (Heidolph multireax) and then placed in a centrifuge (Allegra TM X-12R, Beckman coulter) for 5 $\min$ at $3750 \mathrm{rpm}$.

\section{Analysis of the water phase after extraction}

Cations present in the water phase were measured with a Perkin Elmer, Induced Coupled Plasma Optical Emission Spectrometer (ICP-OES) optima 5300DV (Perkin Elmer, Massachusetts). Results were obtained via a Winlab 32 ICP continuous automated analysis. The ICP-OES has a detection limit of $25-250 \mu \mathrm{g} \cdot \mathrm{L}^{-1}$, with an uncertainty of $1.4-2 \%$. Anions were 
analyzed via a Metrohom 761 Compact ion chromatography (IC) and 762 IC interface with a detection limit of $0.1 \mathrm{mg} / \mathrm{L}$.

Extraction efficiency (E\%) is calculated by:

$$
E(\%)=\left\{\frac{\left(c_{0}-c_{1}\right)}{c_{0}}\right\} \times 100
$$

where $c_{0}$ and $c_{1}$ are the total metal concentration $\left(\mathrm{mgL}^{-1}\right)$ in the aqueous phase before and after metal extraction, respectively. Furthermore, the mole ratio $x_{i}$ of salt extracted over the amount of extractant applied was calculated via:

$$
x_{i}=\frac{n_{i}}{n_{e x}}
$$

in which $n_{i}$ stands for the molar amount of salt extracted and $n_{e x}$ is the molar amount of extractant being applied. The relative selectivity is calculated by dividing $E \%$ of sodium over $E \%$ of the salt of interest from the same experiment. Regeneration percentage $(R \%)$ is calculated by:

$$
R(\%)=\left\{\frac{c_{2}}{c_{3}}\right\} \times 100
$$

where $c_{2}$ stand for the metal concentration $\left(\mathrm{mg}^{-1} \mathrm{~L}^{-1}\right)$ observed in the aqueous phase after

${ }_{15}$ regeneration and $c_{3}$ is the metal concentration $\left(\mathrm{mg} \mathrm{L}^{-1}\right)$ in the organic phase and is determined by $c_{0}-c_{1}$.

The molar concentration of the salt removed was calculated from the difference of the total cation concentrations in the aqueous metal solution before and after the extraction.

\section{${ }_{20} \quad$ Results and discussion}

A white solid powder was obtained after the synthesis of the extractant, [ $\left.\mathrm{N}_{8888}\right][$ monensin]. The melting point was determined to be above $100^{\circ} \mathrm{C}$. Because all experiments with this 
compound were conducted at room temperature, and thus below the melting point, we refer to the product as an ionic crystal instead of IL.

The assumed sodium extraction process with the extractant $\left[\mathrm{N}_{8888}\right][$ monensin] can be written as:

$\left[\mathrm{N}_{8888}^{+}\right]\left[\text {monensin }^{-}\right]_{\text {org }}+\mathrm{Na}_{\mathrm{aq}}^{+}+\mathrm{Cl}_{\mathrm{aq}}^{-} \rightleftharpoons\left[\mathrm{N}_{8888}^{+}\right]\left[\mathrm{Cl}^{-}\right]\left[\mathrm{Na}^{+}\right]\left[\text {monensin }{ }^{-}\right]_{\text {org }}$

The extraction efficiency for a pure sodium solution (I) was found to be $6.1 \pm 0.4 \%$ for the sodium cation and $4.0 \pm 1.7 \%$ for the chloride anion. This gives a molar ratio of chloride to sodium of 0.86 , indicating that the process is mainly based on ion-pair extraction as assumed by equation (4) and not on ion-exchange.

Table 1. Extraction efficiencies ( $E \%)$ and mole ratio of salt extracted $\left(x_{\mathrm{i}}\right)$ for $\left[\mathrm{N}_{8888}\right]$ [monensin] dissolved in toluene (A) of a salt ( $\mathrm{Li}, \mathrm{Na}, \mathrm{K})$ solution compared to the extraction efficiencies of [Na][monensin] (B) and 2-hydroxymethyl-15-crown-5 (C).

\begin{tabular}{lcccccc}
\hline & $\mathrm{E}_{\mathrm{A}}(\%)$ & $x_{\mathrm{iA}}$ & $\mathrm{E}_{\mathrm{B}}(\%)$ & $x_{\mathrm{iB}}$ & $\mathrm{E}_{\mathrm{c}}(\%)$ & $x_{\mathrm{iC}}$ \\
\hline $\mathrm{K}$ & $10.0 \pm 1.0$ & 0.062 & $2.8 \pm 0.3$ & 0.0093 & $2.3 \pm 1.4$ & 0.000013 \\
$\mathrm{Na}$ & $50.8 \pm 0.8$ & 0.54 & $-4.1 \pm 0.9$ & -0.020 & $2.6 \pm 1.5$ & 0.000029 \\
$\mathrm{Li}$ & $9.4 \pm 1.0$ & 0.29 & $1.1 \pm 0.4$ & 0.0049 & $3.2 \pm 1.8$ & 0.00047
\end{tabular}

Extraction efficiency tests performed with a mixed alkali solution (II) provide a measure of ion specificity for sodium, the results are shown in Table 1. It was observed that the extractant was selective towards $\mathrm{Na}$ compared to $\mathrm{Li}$ and $\mathrm{K}$. The extraction results for $\left[\mathrm{N}_{8888}\right][$ monensin] were also compared with the selective removal of $\mathrm{Na}$ by the precursor, sodium monensin ([Na][monensin]) (Table 1). It was found that $[\mathrm{Na}][$ monensin] requires sonication to be dissolved in toluene at room temperature. Moreover, the Na extraction efficiency was found to be negative. This is most likely due to some exchange of the $\mathrm{Na}$ in the [Na][monensin] by $\mathrm{K}$ or Li. The extraction with the crown ether 2-hydroxymethyl-15-crown-5, which is known as a good sodium selective extractant [39], showed poor extraction and exhibited no selectivity for Na using the same alkali salt solution and conditions as for $\left[\mathrm{N}_{8888}\right][$ monensin]. This indicates once more the remarkable selectivity for 
sodium by the $\left[\mathrm{N}_{8888}\right][$ monensin] ionic crystal. Removing $40 \%$ of the dissolved sodium would already be sufficient to reuse irrigation water and significantly reduce corrosion as previously discussed. Furthermore, $x_{\mathrm{iA}}$ for [ $\left.\mathrm{N}_{8888}\right][$ monensin] indicates that for this specific case only half of the ionic crystals extracts a sodium ion. This means that in theory even much more sodium could be extracted, if one could minimize the co-extraction of lithium.

Table 2. Extraction efficiencies $(E \%)$ and mole ratio of salt extracted $\left(x_{\mathrm{i}}\right)$ for a test solution containing the metals $\mathrm{Li}, \mathrm{Na}, \mathrm{K}, \mathrm{Mg}$ and $\mathrm{Ca}$.

\begin{tabular}{cccccc}
\hline & $\mathrm{Li}$ & $\mathrm{Na}$ & $\mathrm{K}$ & $\mathrm{Mg}$ & $\mathrm{Ca}$ \\
\hline$E(\%)$ & $1.0 \pm 1.4$ & $41.1 \pm 0.8$ & $2.1 \pm 1.6$ & $1.5 \pm 1.5$ & $1.2 \pm 1.6$ \\
$x_{\mathrm{i}}$ & 0.028 & 0.80 & 0.023 & 0.026 & 0.014
\end{tabular}

Checking the extraction efficiency of the ionic crystal [ $\left.\mathrm{N}_{8888}\right][$ monensin] for a mixed alkali and earth alkali solution (III) containing the most common metal cations in drinking and irrigation water confirms again the very high selectivity for Na (Table 2). In this case, the Na removal corresponded to a ratio of $0.80 \mathrm{~mol} \mathrm{Na}$ per mol of extractant. Comparing these results to membranes containing monensin or monenin derivatives previously reported in literature confirms that this ionic crystal has a unique selectivity for Na. For example, $0.2 \mathrm{M}$ of [Na][monensin] in octanol has a relative selectivity of 8:1 for Na:Li and 3:1 for Na:K [38], while in this research $0.0004 \mathrm{M}$ of [ $\left.\mathrm{N}_{8888}\right]$ [monensin] dissolved in toluene has a relative selectivity of $41: 1$ for $\mathrm{Na}: \mathrm{Li}$ and 10:1 for Na:K.

Table 3. Regeneration efficiencies $(R \%)$ of the $\left[\mathrm{N}_{8888}\right]$ [monensin] solution after the extraction of alkali metals presented in Table $1\left(E_{\mathrm{A}}\right)$ and there extraction efficiencies $(E \%)$ afterwards towards the same alkali solution (II) applied in Table 1.

\begin{tabular}{ccccccc}
\hline & $R_{\mathrm{HCl}}(\%)$ & $R_{\text {acetic acid }}(\%)$ & $R_{\mathrm{H} 2 \mathrm{O}}(\%)$ & $E_{\mathrm{HCl}}(\%)$ & $E_{\text {acetic acid }}(\%)$ & $E_{\mathrm{H} 2 \mathrm{O}}(\%)$ \\
\hline $\mathrm{K}$ & $32.1 \pm 3.3$ & $30.4 \pm 2.9$ & $28.8 \pm 3.0$ & $8.5 \pm 1.6$ & $8.8 \pm 1.8$ & $11.2 \pm 1.2$ \\
$\mathrm{Na}$ & $100.0 \pm 2.8$ & $100.0 \pm 2.7$ & $56.0 \pm 1.4$ & $6.6 \pm 0.9$ & $8.8 \pm 1.2$ & $38.5 \pm 0.7$ \\
$\mathrm{Li}$ & $9.8 \pm 0.1$ & $9.4 \pm 0.1$ & $9.3 \pm 0.1$ & $9.0 \pm 0.6$ & $9.3 \pm 1.1$ & $9.6 \pm 1.1$
\end{tabular}


Regeneration and reuse of the extractant was investigated with $0.1 \mathrm{M} \mathrm{HCl}, 0.1 \mathrm{M}$ acetic acid and MilliQ water (Table 3). Tests were performed on the toluene solution containing $\left[\mathrm{N}_{8888}\right][$ monensin] that was applied for extraction of a aqueous solution of $1 \mathrm{~g} / \mathrm{L}$ of $\mathrm{LiCl}, \mathrm{KCl}$ and $\mathrm{NaCl}$ presented in Table 1 . Results show that recovery of sodium can efficiently be done by applying an acid (i.e. acetic acid or $\mathrm{HCl}$ ). However, the extractant loses its selective extraction capability following regeneration. It is assumed that the higher regeneration with acids is caused by the protonation of monensin together with the formation of a very water soluble sodium salt. It can be observed from the results given in Table 3 that recovery of the sodium selective form is not possible following acid regeneration. It is thus considered that the ionic crystal should either first be deprotonated before reuse or that the monensin ion is not stable towards acids. Regeneration using MilliQ water retains some sodium selectivity but suffers a lower from reduced overall capacity. Although the levels of extraction and regeneration look very promising, further experiments are necessary to investigate why the ionic crystals cannot be reused. This would indicate if alternative regeneration mechanisms have to be applied or if more stable monensin based complexes have to be developed that still show a high sodium selectivity. Understanding and overcoming this problem will then result in a high selective ionic crystal that can be implemented in ion-exchange resins or membranes.

The solubility of $[\mathrm{Na}]\left[\right.$ monensin] in water was also compared to that of $\left[\mathrm{N}_{8888}\right][$ monensin] in water. When mixing the two compounds with the salt ( $\mathrm{Li}, \mathrm{Na}$ and $\mathrm{K}$ ) solution, it was noticed that $[\mathrm{Na}]\left[\right.$ monesin] formed a white emulsion with the water phase, whereas $\left[\mathrm{N}_{8888}\right][$ monensin] did not and preferred to stick to the inner wall of the test tube. Analysis of the water phase showed that $[\mathrm{Na}]\left[\right.$ monensin] has a low solubility in water of $71.6 \mathrm{mg}^{-1}$ due to its rather hydrophobic character, while $\left[\mathrm{N}_{8888}\right]\left[\right.$ monensin] has an even lower water solubility of $43.6 \mathrm{mg} \cdot \mathrm{L}^{-1}$. From this result, it can be concluded that replacing the sodium ion by the $\left[\mathrm{N}_{8888}\right]$ cation in the monensin salt 
results in an almost twofold decrease of the solubility in water, thereby preventing the loss of this valuable ionic crystal.

\section{Conclusions}

Results showed that the ionic crystal, $\left[\mathrm{N}_{8888}\right][$ monensin] is an ideal extraction agent for selective Na removal. Mixing the ionic crystal with a mixed salt solution containing $\mathrm{LiCl}, \mathrm{NaCl}$, $\mathrm{KCl}, \mathrm{MgCl}_{2}$ and $\mathrm{CaCl}_{2}$ results in a $41 \%$ sodium removal. The extraction mechanism of $\left[\mathrm{N}_{8888}\right][$ monensin] is mainly based on ion-pair extraction. Comparing the sodium selectivity and extraction kinetics with [Na][monensin] or with the known sodium extractant 2-hydroxymethyl15-crown-5 stresses the high selectivity of this novel ionic crystal. Furthermore, changing the Na cation for $\left[\mathrm{N}_{8888}\right]$ to obtain the ionic crystal [ $\left.\mathrm{N}_{8888}\right][$ monensin] resulted in a lower solubility of this ionic crystal into the aqueous phase. Full sodium regeneration of this ionic crystal is possible by applying acidic solutions (0.1 M HCl or $0.1 \mathrm{M}$ acetic acid). However, this regeneration step limits its reuse.

\section{Acknowledgements}

This work was performed in the cooperation framework of Wetsus, European Centre of Excellence for Sustainable Water Technology (www.wetsus.nl). Wetsus is co-funded by the Dutch Ministry of Economic Affairs and Ministry of Infrastructure and Environment, the European Union Regional Development Fund, the Province of Fryslân, and the Northern Netherlands Provinces. The authors like to thank the participants of the research theme "Salt" for the fruitful discussions and their financial support.

\section{References}


1 R. W. Tuthill and E. J. Calabrese, Arch. Environ. Heal. An Int. J., 2013, 34, 197-203.

2 L. A. Sapirstein, W. L. Brandt and D. R. Drury, Exp. Biol. Med., 1950, 73, 82-85.

3 E. J. Calabrese and R. W. Tuthill, Arch. Environ. Heal. An Int. J., 1977, 32, $200-202$.

4 L. Prior, A. Grieve and B. Cullis, Aust. J. Agric. Res., 1992, 43, 1067.

5 R. H. Nieman, Bot. Gaz., 1962, 123, 279-285.

$6 \quad$ J. Han, J. W. Carey and J. Zhang, J. Appl. Electrochem., 2011, 41, 741-749.

7 S. Biswas, V. H. Rupawate, S. B. Roy and M. Sahu, J. Radioanal. Nucl. Chem., 2014, 300, 853-858.

8 B. Onghena, J. Jacobs, L. Van Meervelt and K. Binnemans, Dalt. Trans., 2014, 43, 11566.

${ }_{10} 9$ N. V Plechkova and K. R. Seddon, Chem. Soc. Rev., 2008, 37, 123-150.

10 J. F. Brennecke and E. J. Maginn, AIChE J., 2001, 47, 2384-2389.

11 W. Wang, H. Yang, H. Cui, D. Zhang, Y. Liu and J. Chen, Ind. Eng. Chem. Res., 2011, 50, 7534-7541.

12 M. J. Earle and K. R. Seddon, Pure Appl. Chem., 2000, 72, 1391-1398.

${ }_{15} 13$ T. Welton, Chem. Rev., 1999, 99, 2071-2083.

14 L. Fischer, T. Falta, G. Koellensperger, A. Stojanovic, D. Kogelnig, M. Galanski, R. Krachler, B. K. Keppler and S. Hann, Water Res., 2011, 45, 4601-4614.

15 T. Vander Hoogerstraete, S. Wellens, K. Verachtert and K. Binnemans, Green Chem., 2013, 15, 919-927.

${ }_{20} 16$ S. Wellens, R. Goovaerts, C. Moeller, J. Luyten, B. Thijs and K. Binnemans, Green Chem., 2013, 15, 3160-3164.

17 S. Wellens, B. Thijs and K. Binnemans, Green Chem., 2012, 14, 1657-1665.

18 X. Sun, Y. Ji, F. Hu, B. He, J. Chen and D. Li, Talanta, 2010, 81, 1877-83.

19 T. Vander Hoogerstraete, B. Onghena and K. Binnemans, J. Phys. Chem. Lett., 2013, 4, 16591663.

20 D. Kogelnig, A. Stojanovic, F. Jirsa, W. Körner, R. Krachler and B. K. Keppler, Sep. Purif. Technol., 2010, 72, 56-60.

21 S. Chun, S. V. Dzyuba and R. A. Bartsch, Anal. Chem., 2001, 73, 3737-3741. 
22 M. L. Dietz, J. A. Dzielawa, I. Laszak, B. A. Young and M. P. Jensen, Green Chem., 2003, 5, 682.

23 V. Cocalia, J. Holbrey, K. Gutowski, N. Bridges and R. Rogers, Tsinghua Sci. Technol., 2006, 11, 188-193.

${ }_{5} 24$ S. Dai, Y. H. Ju and C. E. Barnes, J. Chem. Soc. Dalt. Trans., 1999, 1201-1202.

25 A. E. Visser, R. P. Swatloski, W. M. Reichert, S. T. Griffin and R. D. Rogers, Ind. Eng. Chem. Res., 2000, 39, 3596-3604.

26 H. Luo, S. Dai, P. V Bonnesen, A. C. Buchanan, J. D. Holbrey, N. J. Bridges and R. D. Rogers, Anal. Chem., 2004, 76, 3078-3083.

${ }_{10} 27$ H. Luo, S. Dai and P. V Bonnesen, Anal. Chem., 2004, 76, 2773-2779.

28 M. L. Dietz and J. a Dzielawa, Chem. Commun. (Camb)., 2001, 2124-2125.

29 D. Parmentier, S. J. Metz and M. C. Kroon, Green Chem., 2012.

30 V. M. Egorov, D. I. Djigailo, D. S. Momotenko, D. V. Chernyshov, I. I. Torocheshnikova, S. V. Smirnova and I. V. Pletnev, Talanta, 2010, 80, 1177-1182.

${ }_{15} 31$ J. R. Harjani, T. Friščić, L. R. MacGillivray and R. D. Singer, Dalt. Trans., 2008, 4595.

32 P. Nockemann, B. Thijs, T. N. Parac-Vogt, K. Van Hecke, L. Van Meervelt, B. Tinant, I. Hartenbach, T. Schleid, V. T. Ngan, M. T. Nguyen and K. Binnemans, Inorg. Chem., 2008, 47, 9987-9999.

33 A. E. Visser, R. P. Swatloski, W. M. Reichert, J. H. Davis Jr., R. D. Rogers, R. Mayton, S. Sheff and A. Wierzbicki, Chem. Commun., 2001, 135-136.

34 H. Luo, S. Dai, P. V. Bonnesen and A. C. Buchanan, J. Alloys Compd., 2006, 418, 195-199.

35 S. Tang, G. A. Baker and H. Zhao, Chem. Soc. Rev., 2012, 41, 4030-4066.

36 K. Tohda, K. Suzuki, N. Kosuge, H. Nagashima, K. Watanabe, H. Inoue and T. Shirai, Anal. Sci., 1990, 6, 227-232.

${ }_{25} 37$ S. J. Pace and C. Wang, 1996.

38 E. M. Choy, D. F. Evans and E. L. Cussler, J. Am. Chem. Soc., 1974, 96, 7085-7090.

39 Y. Takeda, K. Katsuta, Y. Inoue and T. Hakushi, Bull. Chem. Soc. Jpn., 1988, 61, 627-632. 